\title{
The multidimensional approach to development strategy of marine industry Part II. Multifaceted analysis of the development outlook for the polish marine industry
}

louri N. Semenov, Prof. Szczecin University of Technology

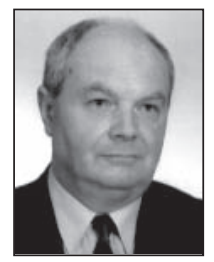

Today the Polish marine industry demands multi-step conversion of its companies into future-oriented enterprises. The article presents some results of the multifaceted analysis of this branch of the Polish economy. Main attention is devoted to identification of the critical barriers to its modernization. It is shown that such purpose as increase of competitiveness requires the correct assessment of various obstacles to innovative changes. Moreover, it is recommended the scenarios approach to the risk minimization of quantitative transformations and qualitative changes in the Polish marine industry. Various scenarios forecasting obstacles impacts are presented. Special attention is focused as on the decision-makers willingness to innovative changes, as on eventual techniques for fruitful overcoming the barriers to accelerated development of the Polish marine industry. Proposals are illustrated by numerous results of fulfilled investigation.

Keywords: Polish marine industry, obstacles to innovative change, maritime transport, risk assessment

\section{INTRODUCTION}

The Polish marine industry had significant growth over the past 60 years, evolving from small regional shipping companies and shipbuilding/shiprepair enterprises into a recognized branch serving international clientele. The first deep-sea ship built in postwar Poland was the small steamship, the 2,540 DWT, which have been launched in the Gdansk shipyard in November, 1948. In 1965, the rate of ships' production for the Poland shipyards reached of peak value, and placed Poland shipbuilding as eighth on the worldwide list of producers.

Rapid development of the Polish marine industry takes place in the beginning of XXI century. So, growth in this sector of the Polish economy has been estimated at between 5.5\% and $6.0 \%$ annually. In 1993-2003 the total number of productive, co-operative, associated and affiliated enterprises was increased from approx. 3790 to more than 8500; however workplaces number was decreased from 120,000 to 100,000 . Last six years, the Poland has a significant presence in such branch of the marine industry as yachting. Now the Polish shipbuilding differs by high exporting possibilities. The exports share of this industry accounts for over $90 \%$ of gross output [12]. Therefore, the Polish construction and repair shipyards employ approx. 20 thousand persons, while the entire shipbuilding industry provides work for nearly 70 thousand persons. Today's development of the Poland's shipping companies are directed to specialized services through timely deliveries, skill management and disciplined crews, as the Poland's shipyards have gained prominence through quality productions of top-class chemical tankers, containerships, super yachts and recreation boats. The key ways of contemporary development of the Polish economy are $[15,17]$ :

$\Rightarrow$ The competitive growth of domestic market which focused on seven major segments of the marine industry, including the shipbuilding, maritime transport, fishing, inland navigation, yachting, ships' service and logistic assistance.

$\Rightarrow$ Support of innovative activity which is concentrated on expansion of scientific and engineering researches. This area includes also training of enterprises personnel.

$\Rightarrow$ Progress of legislative activity which focused on stable perfection of the Polish legal system for comprehensive development of the marine industry.

Unfortunately cyclical character of development of market-oriented economy with its peaks and troughs periods is distinctive feature also for the Polish shipyards and the shipping companies. It occurs for the most part because of absence systemic innovative strategies of management of these segments of the marine industry.

From 2004 the Poland is Member-State of the EU, and has chances for rapid development. In-process adaptation of some Polish companies to the market changes (especially to the recession stage), not enough use of the European experience, as well as the retarded technologies reduces their competitiveness on domestic and foreign markets, and in 
consequence, their chances for commercial success. The main reasons are $[8,12]$ :

$\leftrightarrow$ financial problems, e.g. the increasing prices of metallurgical products and energy supplies, incorrect economical forecast when a contracts on delivery of new-building ships were signed without taking exchange rate risk, just as high labour costs;

$\nLeftarrow$ administrative problems, e.g. insufficient support of innovative activity, as a consequence of incorrect guidelines and the marketing forecast for development ways;

$\leftrightarrow$ unsatisfactory production environment, and as result low labour productivity;

$\downarrow$ risk-averse culture and lack of entrepreneurial spirit of topmanagers.

In turn, the Polish maritime transport is facing some more problems, namely insufficient competitiveness and low operational flexibility. For example, during periods between 1991 and 2000, the Polish shipping companies has tended to drastic limitation of investment program on new ships and sophisticated transshipment equipment. High intellectual potential of the Polish specialists manifested in furtherance to effective adoption of competitive maritime technologies has numerous and varied supporting evidences, including creation of internal regulatory systems and navigation guidelines, permanent monitoring of market forces, designing of successful onshore management systems, and other incentive solutions.
At the same time, error-free choice of prevailing investment strategy is one of the major problems for the Polish shipping companies to solving. In addition to lack of investments into innovative activity there are also other external barriers which hamper both modernizations of a ship equipment, and renovation of the Polish fleet's structure as a whole [3, 13].

First of all, relatively high incompatibility between the Polish production environment and advanced technologies may be important barrier to successful modernizations of any enterprises. This takes place when technology is ,bundled” into complex systems, i.e. one systemic component cannot be replaced or upgraded without necessitating changes in the whole system $[4,10]$. This bundling of technology hampers the production's modernization in some Polish enterprises (e.g. the Polish shipyards, H.Cegielski - Poznań SA. etc.) and the transportation process' improvement in some shipping companies. Principal cause is excessively expensive investments, which are required for purchase and implantation of the bundled technologies. As have shown researches of the author, the Polish enterprises willingly implant the unbundled technologies as more accessible to them because financial and organizational barriers to their performance are considerably smaller, not paying attention to low efficiency of such modernizations.

Furthermore, one of the most common problems is unsatisfactory relationships between scientific communities on the one hand, and business environment on the other hand.

\begin{tabular}{|c|c|}
\hline \multirow{2}{*}{1} & Task - Generalization of foreign experience in innovations implantation. \\
\hline & The objective - Analysis of the modernization practice in the worldwide marine industry. \\
\hline \multirow{3}{*}{2} & $\frac{1}{y}$ \\
\hline & Task - Collection and data generalization for the current situation of the Polish marine industry. \\
\hline & The objective - Identification of development trends for the Polish marine industry. \\
\hline \multirow{3}{*}{3} & $\boldsymbol{\gamma}$ \\
\hline & Task - The investigation of development dynamics of the Polish marine industry. \\
\hline & The objective - Determination of critical points in the Polish marine industry development. \\
\hline \multirow{3}{*}{4} & 支 \\
\hline & Task - Systematization of the causes, entailing generation of obstacles to development. \\
\hline & The objective - Identification of the obstacl \\
\hline & b \\
\hline \multirow{2}{*}{5} & Task - Decomposition and grouping of likely obstacles to development. \\
\hline & The objective - Structurization of probable obstacles to development of the RP marine industry. \\
\hline & $\frac{1}{y}$ \\
\hline \multirow{2}{*}{6} & Task - Investigation of probable obstacles to the innovative process by each-to-each technique \\
\hline & The objective - Identification of the critical and minor obstacles to industry development. \\
\hline \multirow{3}{*}{7} & y \\
\hline & Task - Forecasting of possible obstacles for the sustainable development of marine industry. \\
\hline & The objective - Qualitative assessment of possible scenarios of the RP industry development \\
\hline \multirow{3}{*}{8} & $\hat{\gamma}$ \\
\hline & Task - Mapping of risk distribution for sustainable development of the Polish marine industry. \\
\hline & The objective -Risk assessment of eventual innovative projects. \\
\hline \multirow[b]{3}{*}{9} & $\frac{1}{y}$ \\
\hline & Task - Stratification of forecast's results for innovative transformations within the ma rine industry. \\
\hline & $\begin{array}{l}\text { The objective - Choice of the best development strategy for the Polish marine industry up to } 2040 \\
\text { through multilevel analysis. }\end{array}$ \\
\hline
\end{tabular}

Fig. 1. Sequential analysis of transformation outlooks for the Polish marine industry up to 2040 
According to the Community Innovation Survey, the Polish innovation rate decreased from $37.6 \%$ in the years 1994-1996 to $17.6 \%$ in $1998-2000$. In turn in the years $2002-2004$ the share of innovative enterprises increased to $25.6 \%$. For comparison, this ratio for the UE Member-States increased to $51 \%$ on average. Hence, for the Polish marine industry is more and more important to take part in Community programme named Leadership 2015. This programme assumes a competitive growth in this economic sector through innovation, knowledge and entrepreneurship for the European shipbuilding and shiprepair industry [6]. Despite the actions taken by the Polish shipyards, their economic and financial situation in the last years was still difficult. At present, negotiations for the sale of this business sector being reorganized are under way with private investors. It will allow re-structuring the Polish sea industry. Author recommends analyzing of development outlooks for the Polish marine industry prior to innovations implantation (Fig. 1).

This analysis will help successful modernization of the Polish marine industry as includes both identification of eventual barriers to innovative changes, and simulation of their pernicious impact on reorganization of this industry as whole. The Step 1 of the sequential analysis (Fig. 1) is presented in the Part I of the paper. A basic sketch of the Step 2 and the Step 3 is shown in Introduction. Let's pass to the next steps of our investigations taking into account documents shown in the Table 1.

\section{OBSTACLES TO REORGANIZATION OF THE POLISH MARINE INDUSTRY}

Identification of the obstacles to innovative development of marine industry (Step 4, Fig. 1) plays decisive role so as to take timely steps and to not lose the chances to temper the impact of eventual obstacles. Various inventions as well as innovations play a vital part in technological advancement of the Polish marine industry though the industrial reorganizations in the Polish conditions are sufficiently sophisticated. As result, the maritime transport meets with strong mechanisms creating various barriers to innovative activity. Usually, this is due to the obsoleteness of the industrial environment, and financial or legislative reasons $[8,11]$. In author's opinion take place wider spectrum of the so-called barriers to reorganization of the Polish marine industry.

Let's consider in details the main obstacles to the progress of this business segment, since financial problems as critical "bottleneck".

1. Financial obstacles include:

- lack of investment funds, as consequence of a hindered access to external finance

- competing business priorities, in particular, the pressure for short- term profits

- a high expenses of innovative projects

- a high level of the inflation risk, as well as credit risk and exchange rate risk

- a high cost as raw materials, and energy resources.

In 2006-2007, wide researches of a business environment in the Polish economy have begun. The findings indicate that the high tax rates and overly complication of legal regulation are main barriers to business development. For example, more than $10 \%$ of all entrepreneurs have opinion that the Polish legal system isn't friendly for business activity.

2. Regulative obstacles include:

- deep-rooted traditions of local authority and regional legislative practice

- a low flexibility of obligations under a contract to cargo deliver for various service forms

- enormous number of restrictive laws and government regulations

- complicated and long-term deciding procedures

- scantiness of pre-starting procedures to effective implantation of new ideas.

Other several barriers also hamper innovative development. Since this problem is not enough studied in the Polish literature $[8,15,16]$. Therefore, let's it analyze, taking into account foreign experience $[2,5]$. Some of obstacles have subjective nature. This type of barriers to innovative activity includes individual obstacles, which evolved from mental features of decision-makers, and team obstacles, which developed from the intra-staff relation.

Table 1. Documents used for the problem study

\begin{tabular}{|c|c|c|c|}
\hline № & Title & Author & Date \\
\hline 1 & $\begin{array}{c}\text { Poland and the Knowledge Economy: Enhancing Poland's } \\
\text { Competitiveness in the European Union }\end{array}$ & World Bank, Washington & 2004 \\
\hline 2 & $\begin{array}{c}\text { Strategic Evaluation on Innovation and the Knowledge-based } \\
\text { Economy in relation to the Structural and Cohesion Funds } \\
\text { for the programming 2007-2013. Report to the EC and } \\
\text { Additionally. Country Report: Poland }\end{array}$ & Polish Ministry of Economy, Warsaw & 4.09 .2006 \\
\hline 3 & $\begin{array}{c}\text { Strategy for Increasing the Innovativeness of the Economy } \\
\text { for the years 2007-2013 }\end{array}$ & Technopolis: Walendowski J, Brussels. & 7.07 .2006 \\
\hline 4 & $\begin{array}{c}\text { Defining the Future European Shipbuilding and Shiprepair } \\
\text { industry-Competitiveness through Excellence. } \\
\text { COM (2007) 220 final }\end{array}$ & LeaderSHIP 2015, \\
Brussels & 25.4 .2007$. \\
\hline 5 & $\begin{array}{c}\text { Policy mix for innovation in Poland - key issues and policy } \\
\text { recommendations. DSTI/STR/TIP(2006) }\end{array}$ & $\begin{array}{c}\text { OECD, Directorate for Science, } \\
\text { Technology and Industry , Warsaw }\end{array}$ & 27.06 .2007 \\
\hline 6 & Panorama of transport, KS-DA-07-001-EN-C & Eurostat and EC, Luxembourg & 28.06 .2007 \\
\hline 7 & Analyses and Forecasting Department. Report Economy & Polish Ministry of Economy, Warsaw & 2007 \\
\hline 8 & Statistical Yearbook of Maritime Economy & $\begin{array}{c}\text { Central statistical Office. Statistical } \\
\text { office in Szczecin, Warsaw-Szczecin }\end{array}$ & 2007 \\
\hline
\end{tabular}


3. Subjective barriers include:

a) Individual obstacles:

- top management unawareness of support importance of new ideas

- lack of entrepreneurial spirit

- top management unwillingness to risk

- incorrect guidelines hampering conversion of new initiatives into new product

- a low level of personal liability and motivation to innovative changes

- lack of task awareness, as consequence of poor creativity

- prejudice against innovative changes

- low awareness of environmental issues.

b) Team obstacles, as result of intracompany features:

- a high-level of intra-staff conflicts

- disconnect between first-line managers and personnel

- erroneous actions as a result of unclear explanation of innovative task

- unconvincing or improper motivations of personnel

- a low level of personnel's skills and proficiency.

Besides, the author identified other three problems in development of the Polish enterprises.

Composition of such problems includes:

4. Labor obstacles:

- emigration processes

- lack of job rotation as consequence of difficulty to attract qualified human resources

- skills shortages of the working personnel

- passivity of personnel to innovative changes in connection with possible impact on existing social relationships and personal threat to lose one's work.

5. Industrial obstacles, as result of reformative changes of the Polish economy:

- bundling (systemic interdependency) of manufacturing technologies

- informational, structural and evolutional complexities of innovative changes
- the peculiar environment of eu's enterprises from convergence and phasing-in regions

- a high level of incompatibility of outdated and innovative manufacturing processes

- a high level of the risk of production excess under limited market potential

- a low level of use of nonwaste technologies and as result high production costs

- a high level risk arising from force external to the industry

- a conflict of claims on raw materials and other resources.

6. Operational obstacles, as consequence of delayed access the Poland to the EU:

- a unsatisfactory state of transport infrastructure, e.g. insufficient number of access roads

- a low labour productivity

- a high level of coordination problems, as result of poor experience in logistical activity.

Administrative obstacles play a substantial role in innovative process. The dominant causes of these barriers can be exorbitant bureaucracy and disinclination to meet any innovation, as well as organizational reasons and business motives. Let's analyze administrative obstacles according the Step 5, Fig. 1. First of all, we should formulate definition of structurization process. Structurization is the comprehensive process of information ordering through full division of collected data into separate items, and secondly assembling these items into the hierarchical connected coalition by attributes of causal relations. This process begins on poorly structured informational sets, and has finish on well-structured hierarchical connected coalition. Such well-structured coalition of information attributes relating to administrative barriers is shown in Fig. 2.

7. Administrative barriers:

7.1. Administrative obstacles as result of exorbitant bureaucracy:

7.1.1. scrupulous control of innovative process even if risk-factors have moderate level

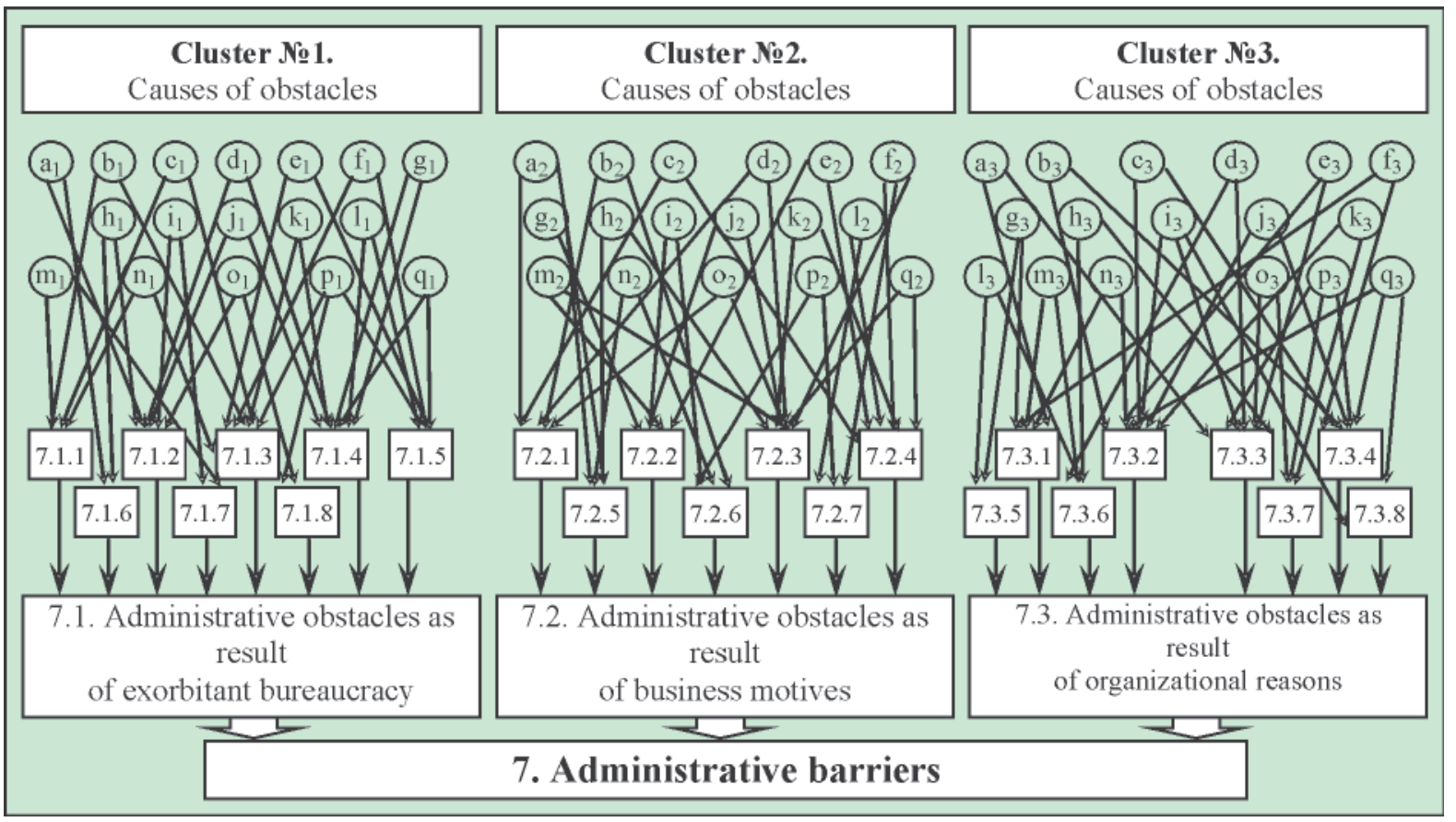

Fig. 2. Structurization of collected data about administrative barriers to innovative development of the Polish marine industry 
7.1.2. inflexibility of management

7.1.3. inconsistent decision-making system

7.1.4. long-term verification of documentations and intricate process of decision-making

7.1.5. insufficient horizontal interoperations in management scheme

7.1.6. a high risk of stoppage of innovative process

7.1.7. the widespread delaying of decision-making

7.1.8. redundant requirements to novelty document feed.

Causes of these administrative obstacles:

$a_{1}-$ formalism and subjective interpretation of transformation results

$\mathrm{b}_{1}-$ voluntarism and frequently changeable priority systems

$c_{1}-$ preference of overall uniformity

$d_{1}-$ excessive level of decision-makers' doubt

$\mathrm{e}_{1}$ - nonacceptance of active debate devoted to the analysis of an innovative policy

$f_{1}-$ low psychological adaptation of decision-makers to new conditions

$\mathrm{g}_{1}-$ excessively level of uncertainty and doubtfulness of decision-makers

$\mathrm{h}_{1}-$ redundant informational feedbacks

$i_{1}$ - extra-formalized schemes of management

$\mathrm{j}_{1}-$ strict hierarchical subordination

$\mathrm{k}_{1}-$ stiff stratified structure of authority and extraordinary centralization of decision-making

$1_{1}-$ communication gaps

$\mathrm{m}_{1}-$ overall normalization of regulations

$\mathrm{n}_{1}-$ nonflexible approach to business planning

$\mathrm{o}_{1}-$ rejection of full responsibility for business results

$\mathrm{p}_{1}-$ overcautious decision-makers

$\mathrm{q}_{1}$ - overcritical approach to new ideas.

7.2. Administrative obstacles as result of business motives:

7.2.1. excessive corporate spirit

7.2.2. distorted business priorities, e.g. choice of priority "short-term profits" as main

7.2.3. uncertain outcome of transformation process

7.2.4. minor public-private cooperation

7.2.5. strong business competition

7.2.6. limited business prospects for new market segments

7.2.7. predominantly aspirations for the status quo in business relations.

Causes of these administrative obstacles:

$\mathrm{a}_{2}$ - lack of a perspicacity and vision of development

$\mathrm{b}_{2}-$ lack of well-defined goals and implantation strategies

$\mathrm{c}_{2}$ - insufficient attention on competitors' business strategies

$\mathrm{d}_{2}-$ doubts about possible profitability of innovative project

$\mathrm{e}_{2}-$ adverse results of marketing research

$\mathrm{f}_{2}-$ growing signs of business recession

$\mathrm{g}_{2}-$ disregard of clientele preferences and owners' wishes

$\mathrm{h}_{2}-$ poor knowledge of business brainpower

$\mathrm{i}_{2}{ }^{2}-$ shortage of skillful and experienced employees

$\mathrm{j}_{2}-$ lack of clientele's demands

$\mathrm{k}_{2}$ - pessimistic trends of business cycle, as result of business slowdown

$1_{2}-$ business corruption and fraud $\mathrm{m}_{2}-$ overstocked market

$\mathrm{n}_{2}-$ panicky prices

$\mathrm{O}_{2}-$ unwillingness to acknowledge own errors and learn from past business defeats

$\mathrm{p}_{2}-$ lack of business acumen

$\mathrm{q}_{2}$ - more than strong traditionalism encouraging conservative business techniques.

7.3. Administrative obstacles as result of organizational reasons:

7.3.1. overstraining criteria of acceptance for innovative risk

7.3.2. overlong period of decision-makings

7.3.3. preferred of overcautious management strategy

7.3.4. overcomplicate procedures of accepting innovative projects

7.3.5. unawareness of development importance of cooperation about new ideas

7.3.6. stiff structure of implementation procedures for innovative projects

7.3.7. deficient system of recognition programs of new ideas and tangible rewards

7.3.8. underestimate of offered innovative decisions.

Causes of these administrative obstacles:

$a_{3}-$ shortage of time for innovative transformations

$\mathrm{b}_{3}-\mathrm{a}$ high risk of undecidability of coordination problems

$\mathrm{c}_{3}-$ lack of profitability evidence

$\mathrm{d}_{3}-$ inability of use of crisis management techniques

$\mathrm{e}_{3}-$ unenviable reputation of inventor-firm

$\mathrm{f}_{3}^{3}$ - lack of will-power to gather and combine resources in the large innovative project

$\mathrm{g}_{3}-$ incorrect or unconvincing business-plan of innovative project

$\mathrm{h}_{3}-$ inability to use of modern techniques for analysis of lead development strategies

$\mathrm{i}_{3}-$ lack of pressure from legislative authorities

$\mathrm{j}_{3}-$ insufficient marketing endeavor

$\mathrm{k}_{3}$ - overanxious by an overmastering force

$1_{3}^{3}$ - over-simplify understanding of innovative problems

$\mathrm{m}_{3}-$ a low level of implementation control

$\mathrm{n}_{3}$ - fastidiousness of top-managers at reviews of new ideas

$\mathrm{O}_{3}-$ unwillingness to acknowledge own errors and learn from past

$\mathrm{p}_{3}-$ overchoice of innovative offers

$\mathrm{q}_{3}-$ overclaiming to new idea.

In remote times, the unfriendliness of a natural environment (the so-called natural barriers to changes) was the major insurmountable obstacles to any transformations. In modern conditions such the natural obstacles include:

8. Natural barriers:

- topographical aspects of the ports;

- hydrological features of the south baltic coastline

- meteorological conditions of offshore zone.

Identification of the critical and minor obstacles to development (Step 6, Fig. 1) is performed through comparison of statistical information $[7,9,11,12]$. Result of data handling for the Polish innovative activity presents Fig. 3.

Financial barriers hold the first place, but administrative barriers and industrial barriers are significant obstacles too. The contradiction between development and obstacles 
may be short-term, long-term or permanent. Barriers to activity evolve by multilevel hierarchy:

$\rightarrow$ barriers hampering the innovative changes in system of mini-level, usually have personal or technological (industrial) nature

$\rightarrow$ barriers hampering the innovative changes in system of middle-level, e.g., operational obstacles by way of required navigation depth for super-large ship

- barriers hampering the innovative changes in system of meta-level, e.g., legal obstacles to ocean-going navigation of single hull tankers.

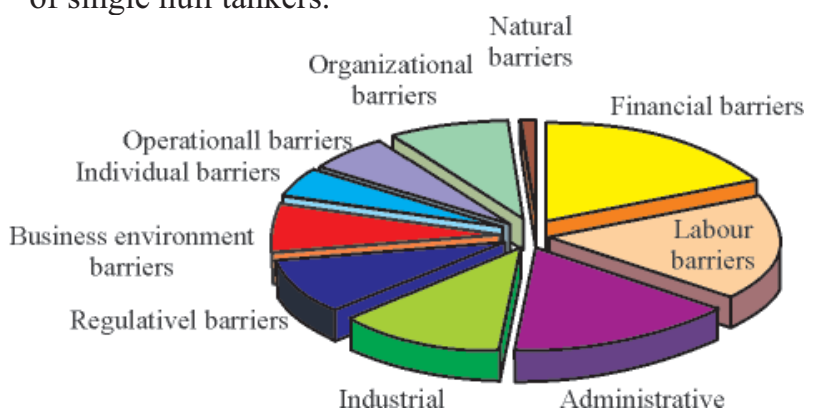

Fig. 3. Comparing shares of main obstacles to development of the Polish marine industry

Let's discuss this statement in next section.

\section{ORECASTING OF THE POLISH MARINE INDUSTRY DEVELOPMENT}

\section{The marine industry as multilevel branch of Polish economy}

Mobility as result of progressive evolution always was remaining key prerequisite for a well-functioning society. Long before the industrial revolution, our civilization have evolved thanks to innovative changes. Such alterations have moved from a propulsive force of wind \& sail or animal power $\&$ wheel to a propulsive plant basing on coal \& steam engine, as well as later to petroleum \& diesel engine. Therefore, transformations of shipping systems occur more than 5500 years from scattered, uncoordinated, and rather homogeneous (monomodal) structures, e.g., mail-coaches or sailing fleet into very oriented, networked, coordinated and heterogeneous structures, e.g. multimodal transport systems distinguishing by high development potential. Today innovative changes in transportation systems excite particular interest as $21^{\text {st }}$ century marks a new stage in their development. As a result, the main goals of the EU transport policy for each Member State are mobility improvement of civilian population and various freight, "bottlenecks" elimination, and optimization of each individual mode of transport both in monomodal and multimodal use, as well as rapid implantation of fault-tolerant vehicles, energyefficient and greener shipping systems $[1,16]$.

In the Polish conditions these problems should be solved considering insufficient compatibility of the overland and waterborne infrastructure, as well as high degree of an openness of the Polish transport systems. According to the last parameter, the Polish marine industry includes two groups of transport systems:

$>$ The first group consolidates the so-called "closed transport systems". Any system is closed composition if it has stable structure, unchangeable during life-cycle, allowing preventive or repair work only. According to the system approach, the closed systems are the isolated objects, which must be designed as high-reliability constructions. E.g. the Polish pipeline systems for transportation of crude oil and gas have numerous the advantages, namely they are an environment-friendly and user-friendliness, as well as differs by stable transport process and the minor transport risk. Closed transport systems have higher assurance factor and survival value. But they are ill-adapted both to the current transformational tendencies and to new ideas, in view of a presence of most if not all obstacles to modernization, and as a consequence, lack of investors' motivations.

$>$ The second group consolidates the so-called "open transport systems". For example, the Polish fleet is open system, because it has flexible structure that can adapt and change according with market demands. Therefore, the modernization realizability of the Polish fleet depends from financial obstacles, just as a place of its components in the functional hierarchy.

Let's reflect on history and modern innovative transformations within the Polish maritime transport. For this purpose, we shall consider some transformations mapping at the various levels of functional hierarchy, namely at the mini-, the middle-, and at the meta-level.

The mini-level. Let's explains this level on one representative illustration e.g., a ship engine. Its one consists from various components, including the combustor, compressor, the gearbox, or piston assembly etc. as well as based on different principles of their assemblage. As have shown author's investigations, the mini-level of the Polish fleet is characterized by high level of innovative activity, in view of practical lack of any obstacles.

The middle-level. Various ships operating within the Polish shipping companies are characteristic example the middle-level for the Polish marine industry. Improvement of these ships implies modification of numerous ship subsystems, namely architecture of ship hull, arrangement of superstructure, layout of an engine-room or placing of a steering mechanism, and others, including generators, pumps etc. The improvement of any such subsystems leads, as a rule, to corresponding alterations in the other subsystems. All this creates numerous obstacles to a continuity and synchronization of innovative process. Up until now, the maritime transport novelties are developed and implemented with a view to the traditional preferences declared by the majority of shipowners, as well as freighters. Unfortunately, often enough the satisfaction of such wishes can be achieved only by a refusal from radical innovations and, as a result, apply the outdated solutions e.g., use of noncompetitive but inexpensive onboard equipment. The contrary situation takes place, when the EU directives or/and business interest requires an advanced environment protection, survivable onboard equipment and high-reliability hull frames, just as improved operational safety or higher comfort of modern vessels. In this situation, the probability of generating of new barriers is very high. Any innovative transformation have the tendency to drastic complication of the day-to-day operations of maritime transport, and increases the costly damages risk as consequence of decision-makers' errors. All this stimulates search of solutions aimed at reduction of total number of eventual obstacles through usability of new solutions.

The meta-level. The regional network of the Polish harbours is one from examples of meta-level. The Polish ports as maritime nodes developed during last 2000 years. For this period their complexity has increased hundredfold. There are two tendencies in seaports development. On the one hand number increase of special-purpose handling terminals (e.g. LNG terminal planning in Świnoujście), and on the other hand broadening of cargoes spectrum, which are simultaneously 
handled on universal terminals. The modern Polish seaports are complex systems, which includes both unmovable installations, namely mooring facilities, fairways, composite breakwaters, warehouses, etc., and mobile equipment including such cargohandling equipment as the portal cranes and wheel loaders. Therefore, their modernization take time and long-term funds allocated to overcoming various obstacles. One more example of the Polish meta-level systems is the fast-developing multimodal transport which has combined various types of overland and waterborne transport.

\section{Investigation of development trends for the Polish marine industry through scenarios approach}

Neglect of barriers identification, as well as, untimely, belated counteractive steps are the critical causes of a failure, which in worst case can lead to bankruptcy of the enterprise. Investigations have been concentrated on modeling the influence of eventual barriers to innovative changes into the Polish marine industry enterprises through three probable scenarios, namely: green, yellow and black (Step 7, Fig. 1.):

The black scenario considers the most complicated situation, when unfavorable concatenation of circumstances leads to generating of unexpected negative system effects at forming of barriers to the innovative development of the Polish marine industry, and as result, timely steps on overcoming barriers are not undertaken.

The yellow scenario considers the situation, when dynamics of forming of barriers to innovative development of the Polish marine industry will be similar to current dynamics, and as result, some timely steps on overcoming barriers are undertaken.

The green scenario considers the situation, when favorable concatenation of circumstances leads to generating of positive system effects at forming of barriers to the innovative development of the Polish marine industry, and as result, significant efforts to overcoming barriers are not required.

At the same time, necessary to take into account that:

$\downarrow$ the current situation about chances and obstacles to stable development of the Polish marine industry were calculated using the numerous information including reviews of the separate Polish enterprises, and annual reports of the Polish government illustrating transformation processes in the Polish economy (see Introduction);

\ the barriers' type, their frequency and amplitude were categorized according to analysis of various statistical data. During investigations take into account that any obstacle preliminarily classified as low probable, can change the status and will be transformed into critical barrier under a circuit of possible events, and at last

- barriers to steady development of the Polish marine industry should be investigated on the mini-level, the middle-level, and at last the meta-level. For example on the mini-level of the Polish marine industry, innovative project of new-building ship should be study according ability to overcoming barriers to perform such key functions as propulsion, capacity and safety. The specific targets of detailed investigations are determined by levels of informational and logical certainty for three scenarios of possible events.

Researches included four phases:

1. Simulation of negative impacts on the innovative project environment (Fig. 4).

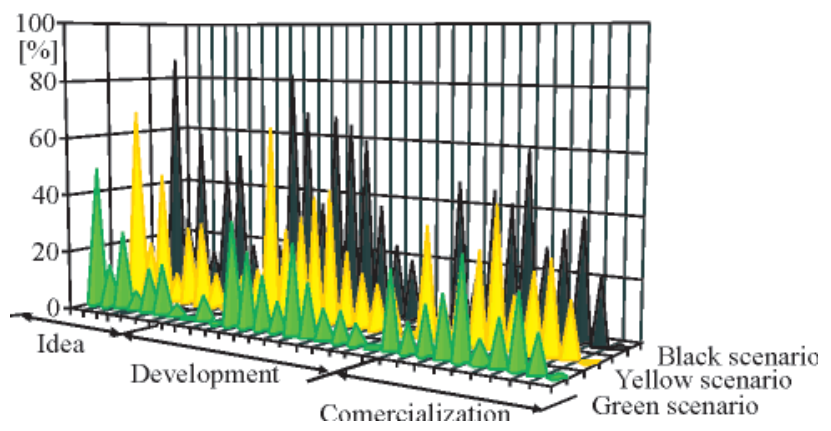

Fig. 4. Simulation of frequency and amplitude of negative impacts on the innovative project environment

2. The forecast of the barriers' impact hampering the successful implementation of an averaged capital-intensive project for the mini-level of the Polish marine industry (Fig. 5).

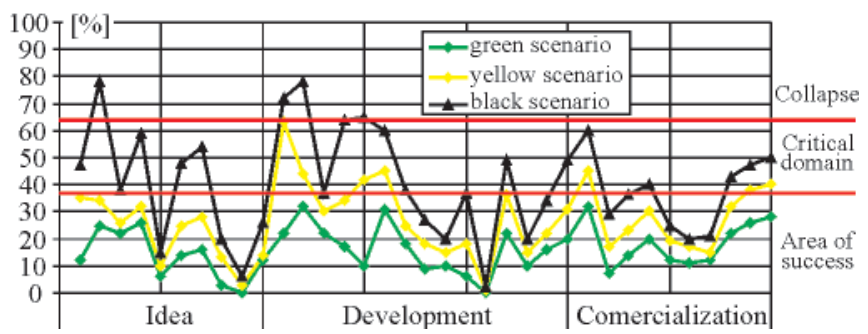

Fig. 5. The forecast of the barriers' impact hampering the successful implementation of an averaged capital-intensive project.

Simulation result for the mini-level of the Polish marine industry

3. The forecast of probable barriers to innovative development of the Polish marine industry up to 2040 (Fig. 6).

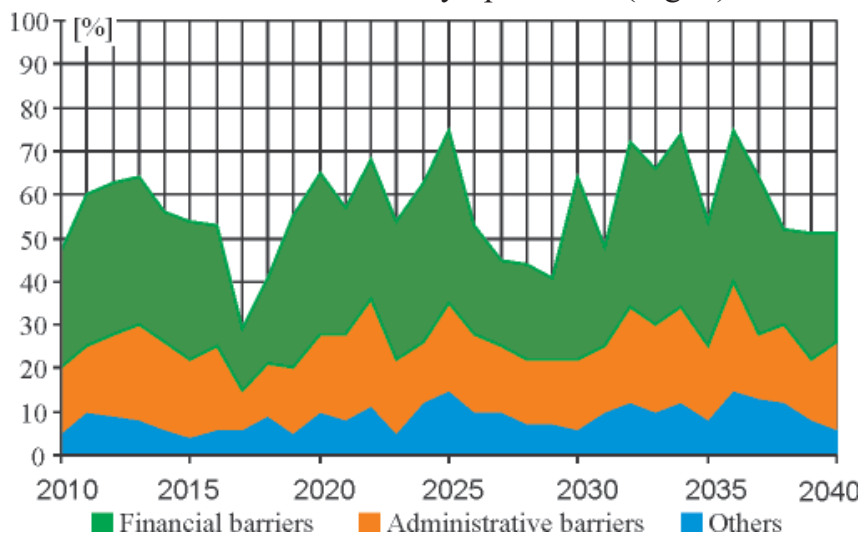

Fig. 6. The forecast of probable obstacles to innovative development of the Polish marine industry up to 2040. Simulation of generating possible barriers to innovative activity

4. Estimation results of multi-step conversion of its companies into future-oriented enterprises of the Polish marine industry up to 2040 (Fig. 7).

\section{RISK ANALYSIS OF INNOVATIVE TRANSFORMATIONS}

The modern business world is opened to various social and technological changes through implantation of new investing projects. In many aspects such projects focuses on either increase of volume of freight traffic, or transportation safety, as well as feeling of high comfort for first-class passengers. The each enterprise of the Polish marine industry has different capability for solution of described problems. Success depends from next factors:

$\diamond$ professionalism level of all groups of decision-makers 
$\diamond$ accuracy of marketing researches and forecast precision of European development trend

$\diamond$ correctness and opportuneness of organizational changes

$\diamond$ strong personal motivation to innovative renovations.

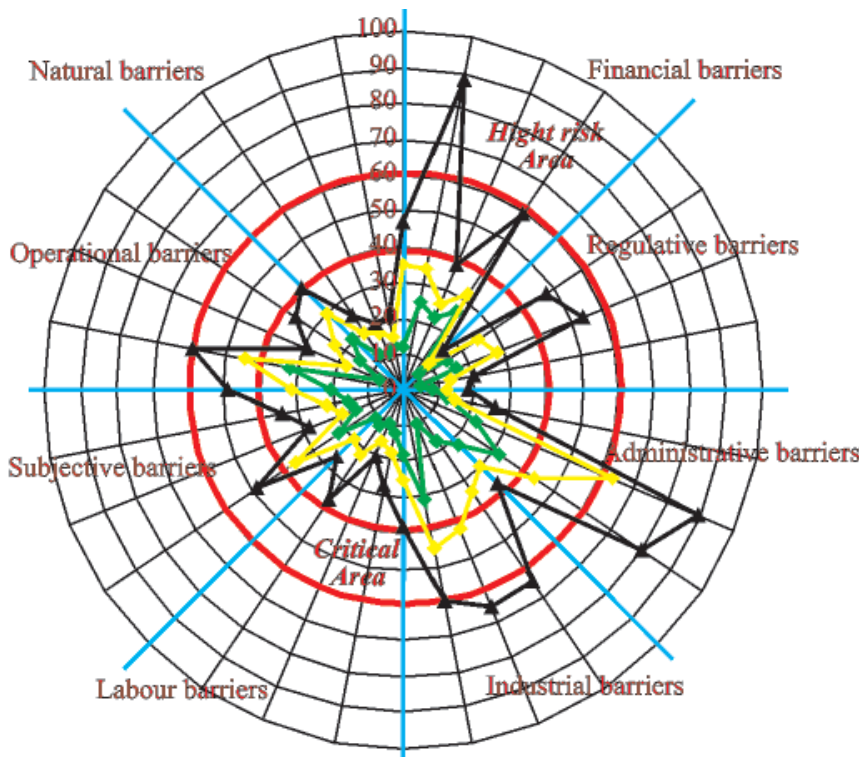

$\multimap$ Green scenario - Yellow scenario $\longrightarrow$ Black scenario

Fig. 7. Estimation of modernization risks for meta-level of the Polish marine industry up to 2040

Several conclusions from the results of risk investigation for an averaged capital-intensive project relating to Fig. 5:

- According to the black scenario the most risky are the first stage and the second stage of an innovative project's implementation, so they have approximately equal probability of a premature stoppage of the project (the first and second peaks of a collapse domain) as a consequence of impact from regulative, financial and administrative obstacles.

- The most of the raised risk peaks situated in critical domain is typical for the first stage and the last stage of the project implementation. It can be connected with impacts of financial and operational barriers

- According to the most realistic scenario (yellow) the first stage of the innovative project is favorable. That is connected with a high intellectual potential of innovators and the scientists working for the marine industry. The most risky is the second stage according to the yellow scenario. It can be explained by synergetic effects from cumulative impacts of industrial, subjective, financial obstacles.

For the purpose of impact minimization from various obstacles to the sustainable development of the Polish marine industry it is necessary to concentrate attention to overcoming subjective barriers through various trainings of the personnel of the enterprise and to search of new stimulus. Training should focus on the opportunities to improve quality and profitableness of the Polish transport system through the study of best examples of the advantage of the European shipping companies. Under these circumstances should be taking into account, on the one hand the current world trends of shipbuilding development and the specificity of the coastal Regions, and on the other hand the eventual barriers to successful implementation of new solutions and methods of their overcoming.

The main inference from performed researches: It concludes that integration of the above mentioned barriers and fatal decision-making logic can cause loss of competitiveness of the Polish marine industry within the next $15-20$ years.
The very important are the following actions to overcoming operational barriers to modernization the middle-level the Polish marine industry:

- to investigate evolution both shipbuilding products and advanced service technologies relative to critical factors of success, with purpose of early verification of a selected innovations with the additional control of compatibility between this ones and standard shipbuilding products implanted into large-scale commercialization earlier;

- to determine of all interested actors and their involving in the innovative process with the purpose of compatibility improvement within the limits of circuits "idea-product" through effective transfer of RDI-results (advanced technologies, new techniques of management etc.) into shipbuilding, and shipping services;

- to put into practice a pilot projects within the marine cluster for deep verification as actual necessity of these projects in the authentic conditions of the Polish market, as well as practical serviceableness and profitability of the new techniques and technologies,

- to liven up business contacts with stable and eventual clientele (shipowners, freighters etc.) for information about new potentialities of the future-oriented enterprise, and at last

- to carry out monitoring changes of rivalry on targeted sector of the market with the purpose of permanent analysis of the current vulnerabilities of the enterprise and weaknesses of the developed innovative project, to predict a basic kinds positive synergies effects, just as negative revenge effects. The assembled diagram of attenuations and intensifications of barriers to quick development of the Polish marine industry shown on Fig. 6.

As laid down by $[11,12,16]$ success of the Polish marine industry depends on the long-term policy of regional development, and ability of decision-makers to use such Polish values, just as introduction into the EU, creative potential of the Polish scientists and skills of domestic workers. Therefore, innovative changes on meta-level must meets five objective, including market demands; significant competitiveness; proven technological supremacy and reliability; environment-friendly, and at last compatibility with technological surrounding.

In the resume, let's enumerate the basic opportunities and threats of innovative transformations (Fig. 7). One of the most unexpected results is the litany of development factors of the Polish marine industry on meta-level which haven't any improving effects, or cover minor influences on investors' solutions. These factors include:

$\Rightarrow$ specifics of exploiting the polish fleet (operational barriers)

$\Rightarrow$ the climate in location points of the polish seaports (natural barriers)

$\Rightarrow$ experience and education level of the polish seafarers (labour barriers)

$\Rightarrow$ number of marine agencies contributory with the polish seaports (subjective barriers).

The second inference from attained results. It concludes that introduction of the advanced innovations in the Polish seaports, feeder transport or assisting fleet can leads to extraordinary increase in competitiveness of the Polish maritime transport as the whole, even when other components of this transport have not been modernized simultaneously. This conclusion proves by high mastery and wide knowledge of the Polish managers.

The third result from achieved investigations. It concludes that takes place six factors which directly impact on risk 
magnitude for multistage conversion of the Polish maritime transport, namely:

A current market situation

ᄉ availability of investing funds

A positive trends of economical index for best innovative practice

A readiness of a shipowners, freighters etc., to innovative changes

A eligibility and compatibility of a new solutions relates to loading/unloading operations

ᄉ operational efficiency of feeder modes associated to maritime transport.

According to these appraisals for the Polish fleet have possibilities first of all, to entry on new sectors of market e.g., LNG transportation or marine tourism, as rapid extension of the commercial market on the ferries sector of the short-sea shipping within the Baltic Sea [1].

The most productive are the following ways of stimulation of an innovative activity on all levels of the Polish marine industry:

+ increasing of legal support for relationships between the inventors and authorities, in purpose of strengthening co-operations within the "knowledge and innovativeness triangles"

+ expanding of informational and financial support of the innovative clusters as a basis for flexible public-private cooperation within framework of the Polish marine transport

+ painstaking identification and a strict control of political, marketable and social risk-factors, for overcoming the usual and atypical obstacles to innovative activity; Fig. 8 and Fig. 9 present a forecast of changes of barriers and frequency of their development

+ indicating the new ways for large-scale commercialization of innovative ideas.

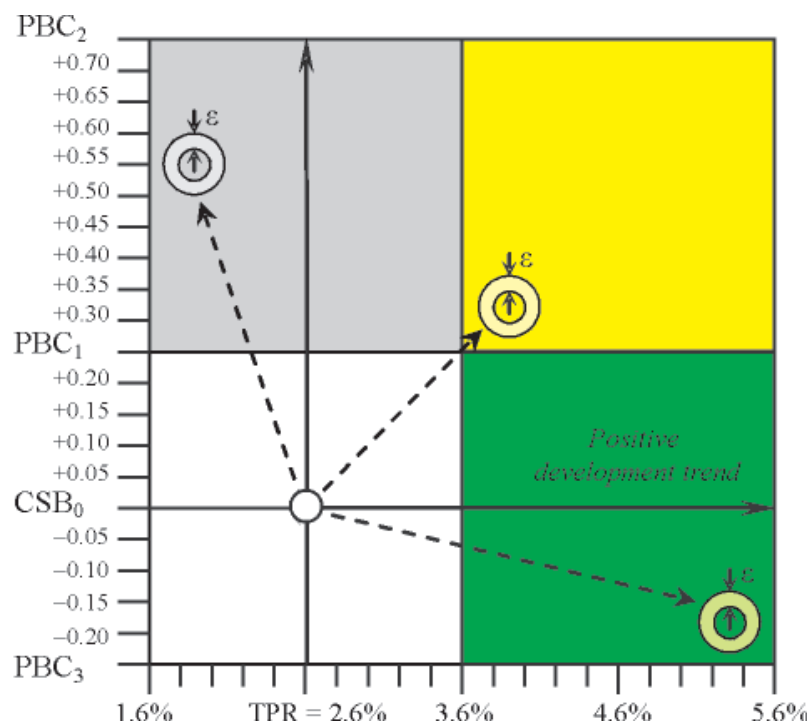

Fig. 8. Simulation results of probable changes of barriers impacts up to 2015. $\boldsymbol{\varepsilon}$-possible calculation error; $\boldsymbol{P B C}$-Possible Barriers Change; $\boldsymbol{C S B}-$ Current State of Barriers to development of the Polish marine industry; $\boldsymbol{P} \boldsymbol{B} C_{1}$ - the lower border of possible increase of barriers for black and yellow scenarios; $\boldsymbol{P B C}_{2}$ - the highest border of possible

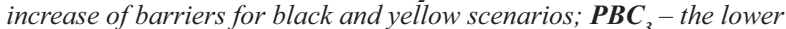
border of possible reduction of barriers for green scenario; $\boldsymbol{T P R}$ - Turnover Profitability Rate

Therefore, the Polish top-managers always should be amicable to new ideas, and able to take risk; the Polish middle-

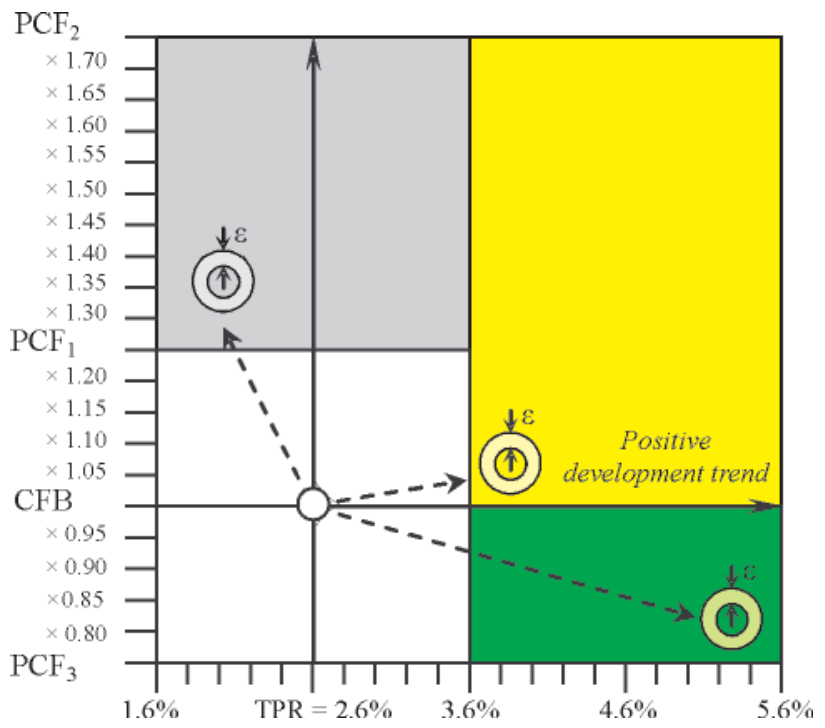

Fig. 9. Simulation results of probable frequency of barriers development up to 2015. $\boldsymbol{\varepsilon}$-possible calculation error; $\boldsymbol{P C F}$ - Possible Change of barriers development Frequency; $\boldsymbol{C F B}$ - Current Frequency of Barriers

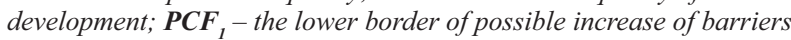
for black and yellow scenarios; $\boldsymbol{P C F}$ - the highest border of possible increase of barriers for black and yellow scenarios; $\boldsymbol{P C F}_{3}-$ the lower border of possible reduction of barriers for green scenario; TPR - Turnover Profitability Rate

managers sometimes should have chance to fail; the Polish firstline managers should be focused on achievement of hopeful results during all realization of an innovative project, and at last all managers should be able to draw correct conclusions as from successes, as and defeats.

In the finale, some recommendations for successful transformation of the Polish marine industry, considering on the one hand the strengths and the opportunities basing on high creative potential of the Polish managers, and on the other hand the weakness and the threats connected to various obstacles to development of this sector of the Polish economy, taking into account $[6,11,12,17]$ :

1. The Polish decision-makers should more focus their effort and attention on the maritime transport development as main mode of European multimodal transport system. Success depend on improvement program of various types of overland and waterborne transport, and serving the Poland's gateways, inland waterways and seaports i.e. correct choice of development strategy either "Expansion of the market through increase in competitiveness of the current offer", or the radical ones - "Capture a market through innovative spurt".

2. The Polish marine industry can be more competitive through orientation to the co-evolution principle, when all components of this industry are simple in designing, proved by practice and compatible each-to-each at all hierarchical levels.

3. In conditions of demand-based business relationships, the Polish maritime transport through high quality and efficiency become the key part of the Polish marine industry.

4. In order to be usable, the Polish transport system integrating overland and waterborne modes must reach a critical mass of innovative solutions, be based on the principle of maximization of risk- free that can be received through flexibility, reliability and economical efficiency. This critical mass must answer to two requirements:

- sufficiency, i.e. improved maritime transport should be widely available for competitive use by forwarding agents, as well as regular and irregular passengers 
- not overstrain, i.e. improved maritime transport should guarantee such possible profit which is high proportionally in comparison with transportation risks.

5. For any shipping company, any part of the Polish transport infrastructure should be usable, and all parts of that transport infrastructure should be usable. Its requirement is very important especially at make-ready to EURO 2012 for full and integrated service of fans, as well as foreign tourists and domestic travelers.

6. In the renovation of the Polish maritime transport, every change is an opportunity for performance improvement. Such improvement must be supported:

- by adequate marketing and error-free managing solutions

- by conflict-free organizational changes within the Polish marine industry

- by obstacles-free frameworks which first of all, should be focused on preservation of clientele's trust, and secondly not to depend from longstanding familiarity of governing body anyone shipping company or anyone shipyard with authorities.

\section{FINAL CONCLUSIONS}

The common goals of the EU transport policy for each Member State are mobility improvement of inhabitants and various freight, "bottlenecks" elimination, and optimization of each individual mode of transport both in monomodal and multimodal use, as well as rapid implantation of faulttolerant vehicles, energy-efficient and greener maritime transport.

Transformation of the Polish marine industry should be performed in some steps, beginning from identification of eventual barriers to innovative changes, and simulation their pernicious influence on reorganization of this industry as whole.

Up to 2040 year the Polish marine industry can meet with three waves of strong mechanisms creating various barriers to innovative activity. The first wave will occupy the period 2012-2014, next amplification of barriers to development will take place between 2022 and 2025, and third wave package will occupy period 2034-2037. Traditionally, this phenomenon explains either by obsoleteness the Polish industrial environment, or by financial or legislative reasons. As follow from performed investigations, each enumerated wave will be creating under strong synergetic mechanisms.

Any innovative transformation have the tendency to drastic complication of the day-to-day operations of maritime transport, and increases the costly damages risk as consequence of decision-makers' errors. All this stimulates search of solutions aimed at reduction of total number of obstacles through rise both reliability and usability of new solutions. At the green scenario of innovative activity, the size of barriers can be on the average reduced by $15-18 \%$.

Innovative solutions should be analyzed in three-level space, on the mini-, the middle-, and at last the meta-levels. For example, innovative projects for merchant ships can be analyzed according to key functions including propulsion, equipment and safety system. The degree of detail needed in simulation was determined by level of informational certainty.
On the mini-level of the Polish marine industry main attention should be focused to training of enterprise personnel. Training be supposed to concentrate on the opportunities to improve quality and profitableness of the Polish transport system through the analysis of best examples of the first-rate European shipping companies, taking into account the current world trends of shipbuilding development, the specificity of the coastal Regions, and the eventual barriers to successful implantation of new solutions, as and methods of their overcoming.

The middle-level of the Polish marine industry is the most promising to fast development. The very important are the few following actions to overcoming operational barriers to modernization, namely detailed screening of selected innovations and service technologies in relation to critical marketable factors, their verification and the additional control of compatibility between these ones and market demands, and at last, preparatory measures activities for earlier large-scale commercialization of new product.

For acceleration of overcoming usual and atypical obstacles to the realization of innovative projects at all levels of the Polish marine industry is necessary to increase legal support co-operations within the "knowledge triangle"; to reinforce partnership the inventors and regional authorities, as well as to expand informational and financial support of the innovative clusters through elasticity of public-private cooperation; carefully to identify and strictly to supervise of political, social and marketable risk-factors, and at last to search the new pathways of successful innovations implantation and their large-scale commercialization. In this case, at the green scenario of innovative activity, the barriers frequency to the Polish marine industry development can be on the average reduced by $22-25 \%$.

The error-free choice of development strategy of the Polish marine industry and end-to-end advancement of the innovative transformations are able to give fruitful results consisting in 10-14\% decrease of revenge effects, and in $8-10 \%$ increase of such effects as competitiveness, profitability and safety of improved transport system.

\section{Acknowledgment}

This paper was supported by the Polish State Committee for Scientific Research. 2008.

\section{BIBLIOGRAPHY}

1. Arndt M., Pauli A. Trans-European Transport Networks (TEN-T) in the Baltic Sea Region, Policy Recommendations, Erkner, 22 December 2005

2. Bass, H.-H., Ernst-Siebert, R. SME in Germany's maritime industry: innovation, internalization and employment; International Journal of Globalization and small Business, Vol. 2, Number 1, 24 June 2007 pp.15-33

3. Birla M. FedEx: How the World's leading Shipping Company keeps innovating and Outperforming the Competition, Wiley, John \& Sons, 2005

4. Boutellier, R., Gassmann, O., and von Zedtwitz, M.: Managing Global Innovation: Uncovering the Secrets of Future Competitiveness, $2^{\text {end }}$ ed., Springer, Berlin, 2000

5. Evangelista R., Sirilli G. Innovation in the service sector. Results from the Italian Statistical Survey, Technological Forecasting and Social Change, 58, 1998

6. European Commission. LeaderSHIP 2015: Defining the Future European Shipbuilding and Shiprepair industry-Competitiveness through Excellence. COM (2007) 220 final, 25.4. 2007 
7. Eurostat. Panorama of transport. Eurostat and European Commission, 2007

8. Kajenska I., Adamowicz E., Kurzydlowski K. Barriers in Innovation and Technology Transfer in Poland. $5^{\text {th }}$ triple Helix paper, Turin, Italy, 18-21 May 2005

9. Niedbalska G. Innovation Activities in Polish Industry in 19982000: Main Results from the GUS 2001, Innovation Survey,

Working Paper № 25, SSEEC, UCL, London, $22 \mathrm{p}$

10.Pearce R.: Globalization of $R \& D$ : key features and the role of $T N C s$, Proceedings of the Expert Meeting Globalization of $R \& D$ and Developing Countries, United Nations Conference on Trade and Development, Geneva, pp.29-42, 2005

11.Polish Ministry of Economy. Strategy for Increasing the Innovativeness of the Economy for the years 2007-2013. Warsaw, 4 September 2006

12.Polish Ministry of Economy: Analyses and Forecasting Department. Report Economy: Poland 2007, Warsaw 2007

13.Roe M.S. The commercialization of East European liner shipping: the experience of Poland Maritime Policy \& Management, vol. 26, Issue 1, January 1999, p 69-79

14. Statistical Yearbook of Maritime Economy, Central statistical Office, Statistical office in Szczecin, Warszawa-Szczecin, 2007
15.Walendowski J. Strategic Evaluation on Innovation and the Knowledge-based Economy in relation to the Structural and Cohesion Funds for the programming period 2007-2013. Report to the European Commission, Directorate-General Regional Policy Evaluation and Additionally. County Report: Poland, Brussels, 7 July, 2006

16. Wojnicka E., Rot P., Tamowicz P. Regional Innovation System in Pomeranian Province of Poland. $6^{\text {th }}$ International Conference on Technology Policy and Innovation. Kansai Science City, 12-15 August, 2002

17.World Bank. Poland and the Knowledge Economy: Enhancing Poland's Competitiveness in the European Union. ISBN 8389188-21-X. Washington D.C., 2004.

\section{CONTACT WITH THE AUTHOR}

Prof. Iouri N. Semenov

Faculty of Marine Technology

Szczecin University of Technology

AL. Piastów 41,

71-065 Szczecin, POLAND

e-mail: jusiem@ps.pl

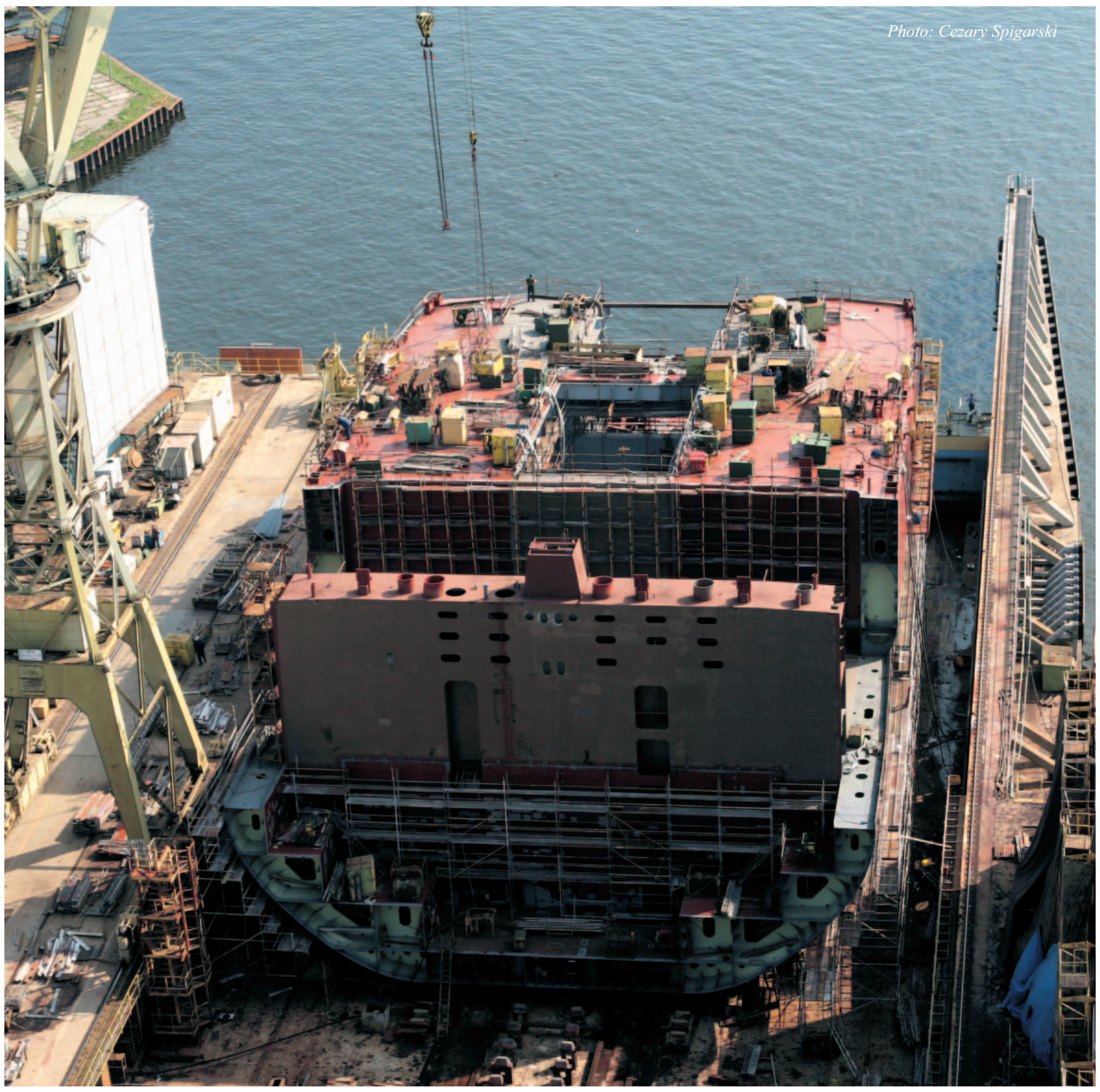

